\title{
Interactive feedbacks of climate, mineralogy and microbiological communities on soil carbon: A deep soil warming experiment.
}

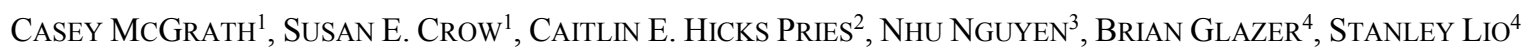

${ }^{1}$ Department of Natural Resources and Environmental Management, University of Hawaii Manoa, Honolulu, HI, USA 96822 , mcgrathc@hawaii.edu, crows@hawaii.edu

${ }^{2}$ Department of Biological Sciences, Dartmouth College, Hanover, NH, USA, 03755, caitlin.pries@dartmouth.edu

${ }^{3}$ Department of Tropical Plant and Soil Sciences, University of Hawaii Manoa, Honolulu, HI, USA 96822, nhu.nguyen@hawaii.edu

${ }^{44}$ Department of Oceanography, University of Hawaii Manoa, Honolulu, HI, USA 96822, glazer@hawaii.edu, hlio@hawaii.edu

Soils with high potential to drawdown carbon (C) from the atmosphere, such as volcanic ash-derived Andisols, could aid in mitigating climate change while long term solutions are enacted. Poorly and non-crystalline mineral associated organic matter is stabilized and protected from decomposition, resulting in large stocks of very old $\mathrm{C}$ in some Hawaiian Andisols. Evidence from non-Andic soils suggests that increased soil temperature escalates microbial activity in the soil. Consequently, soil respiration rates increase throughout the soil profile and decrease $\mathrm{C}$ stocks, if metabolic losses outweigh input gains. However, how the intensive warming predicted with climate change by 2100 will impact $\mathrm{C}$ cycling and storage in Andisols is unknown. On a 200 $\mathrm{m}^{2}$ hillslope of a wet montane Andisol, soil was heated using a regression design allowing for a soil temperature gradient of ambient to $+4^{\circ} \mathrm{C}$ across sampling depths $(20,40,60,80$, and $100 \mathrm{~cm})$. After a year of deep soil warming during which soil respiration and flux throughout the soil profile was measured, the mean $\mathrm{CO}_{2}$ produced ranged from 0.15 to $9.0 \mathrm{~g} \mathrm{CO} 2 \mathrm{~m}-3 \mathrm{hr}-1$ across the gradient of temperature and depth. At each sampling point, key soil properties including carbon, nitrogen, $\mathrm{pH}$, noncrystalline minerals, 16S and ITS DNA sequencing were measured. Principal component analysis revealed a clear depthdependent separation of the primary drivers of $\mathrm{CO}_{2}$ produced. Unlike any other deep soil warming experiment to date, generalized additive modeling showed no significant $\mathrm{CO}_{2}$ response to augmented soil temperature below $20 \mathrm{~cm}$ in the profile. Multimodal analysis confirmed the hypothesis that high concentrations of poorly and non-crystalline minerals (i.e., hydroxylamine hydrochloride extractable $\mathrm{Al}+0.5 \mathrm{Fe}$ ) were the primary driver of the lack of $\mathrm{CO}_{2}$ response, followed by high relative soil moisture and high nitrogen content when factored by sampling depths. The significant lack of increased $\mathrm{CO}_{2}$ production in response to warming due to poorly and non-crystalline mineral protection suggest Andisols will not cause a positive feedback to climate change, unlike any other warmed soils. Therefore, Andisols should be considered high priority restoration or protection areas when considering management and policy decisions prioritizing climate action plans. 